\title{
Regioselective Synthesis of Polysubstituted Pyridines via Hetero Diels-Alder Reaction of Isotellurazoles with Acetylenic Dienophiles
}

\author{
Kazuaki Shimada, 'Yukichi Takata, Yu Osaki, Akiko Moro-oka, Hisashi Kogawa, \\ Maiko Sakuraba, Shigenobu Aoyagi, Yuji Takikawa, and Satoshi Ogawa \\ Department of Chemical Engineering, Faculty of Engineering, Iwate University, \\ Morioka, Iwate 020-8551, Japan
}

\begin{abstract}
Treatment of substituted isotellurazoles or their $T e$-oxides with acetylenic dienophiles efficiently afforded polysubstituted pyridine derivatives through a pathway involving heteroDiels-Alder reaction of isotellurazoles and the subsequent tellurium extrusion from the intermediary cycloadducts. (c) 2009 Elsevier Science. All rights reserved.
\end{abstract}

Keywords: Isotellurazole; Hetero Diels-Alder Reaction; Acetylenic Dienophiles; Polysubstituted Pyridine; Azafluorenone

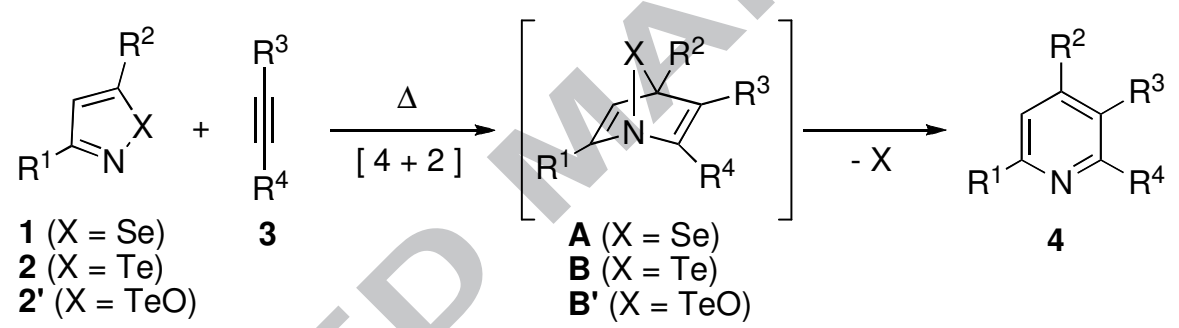

Polysubstituted and fused pyridine cores have been found in a wide variety of naturallyoccurring polycyclic alkaloid skeletons having biological, pharmaceutical, and agrochemical activities, and studies on efficient synthesis of pyridine ring systems preserves a considerable importance in current organic synthesis in spite of the long history of pyridine chemistry. Among the modern methodologies for the syntheses of pyridine rings, thermal reactions of chalcogenand nitrogen-containing five-membered heterocycles with dienophiles have been extensively studied. However, synthetic application of such compounds has been limited within the area of oxygen- or nitrogen-bridged five- or six-membered heteroaromatics due to the easiness in preparation and their treatability. ${ }^{1-5}$ Among the five-membered heterocycles bearing a chalcogen atom, tellurazoles and isotellurazoles have been presumed to behave as heavy chalcogen-bridged reactive azadienes based on the relatively low heteroaromaticity of tellurium-containing fivemembered heteroaromatics ${ }^{6}$ and the subsequent feasible extrusion of elemental tellurium from the intermediary cycloadducts B or B' under mild reaction conditions. However, only limited preparative methods for tellurazoles and isotellurazoles had been reported within these decades in spite of their potentiality as reactive heterodienes. ${ }^{7,8}$ In the course of our studies on syntheses and reactions of higher-row chalcogen-containing heterocycles, we reported a convenient preparation

\footnotetext{
* Corresponding author. Tel \& Fax: +81-19-621-6324; e-mail: shimada@iwate-u.ac.jp
} 
of isotellurazoles 2 by the way of reaction of $T e$-alkenyl tellurocarbamates ${ }^{9}$ with hydroxylamine $O$-sulfonic acid involving intramolecular $\mathrm{S}_{\mathrm{N}} 2$ replacement on the oxime nitrogen atom followed by deoxygenation of $T e$-oxides $2{ }^{\prime}{ }^{10}$ These successful results envisaged us to the attempts for the synthesis of pyridine ring systems using hetero Diels-Alder reaction of $\mathbf{2}$ or $\mathbf{2}$ '. Here, we describe a new and efficient conversion of $\mathbf{2}$ or $\mathbf{2}$ ' into polysubstituted pyridines $\mathbf{4}$ in a high regioselective manner via hetero Diels-Alder reaction with acetylenic dienophiles under mild reaction conditions. Short-step construction of biologically intriguing 2-aza- and 4-azafluorenone alkaloid skeletons from the resulting pyridines $\mathbf{4}$ are also described in this paper.

Isotellurazoles $\mathbf{2}$ and their $T e$-oxides 2' were prepared easily from phenylacetylene or 1-hexyne by using our reported method. ${ }^{9}$ However, all attempts for deoxygenation of isotellurazole Teoxides 2' bearing two alkyl groups at the C-2 and C-4 positions were unsuccessful in spite of applying various reducing agents.

Isotellurazoles $\mathbf{2}$ and $\mathrm{Te}$-oxides $\mathbf{2}$ ' were thermally stable enough up to $150{ }^{\circ} \mathrm{C}$ when heated in the absence of any electrophilic reagents. However, when a $\mathrm{CH}_{2} \mathrm{Cl}_{2}$ solution of $\mathbf{2 a}\left(\mathrm{R}^{1}=\mathrm{CH}_{3}, \mathrm{R}^{2}\right.$ $\left.=\mathrm{C}_{6} \mathrm{H}_{5}\right), \mathbf{2} \mathbf{b}\left(\mathrm{R}^{1}=\mathrm{R}^{2}=\mathrm{C}_{6} \mathrm{H}_{5}\right)$, or their corresponding Te-oxides, $\mathbf{2} \mathbf{a}$ ' or $\mathbf{2} \mathbf{b}$ ', was treated with dimethyl acetylenedicarboxylate (DMAD), all substrates underwent facile conversion into the corresponding pyridine derivative $\mathbf{4 a}$ or $\mathbf{4 b}$, respectively, even at room temperature along with the gradual extrusion of elemental tellurium. Similar reactions of isotellurazoles $\mathbf{2}$ or isotellurazole Te-oxides 2' with various acetylenic dienophiles also gave pyridine derivatives 4 in high to moderate yields, and sole regioisomers of $\mathbf{4}$ were obtained in all cases using unsymmetrical acetylenic dienophiles bearing an electron-withdrawing group (EWG). Especially, pyridine 4c, synthesized from $\mathbf{2 a}$ and methyl propynoate, were identical in all respects with those of the reported product. ${ }^{11}$ These results indicated that both $\mathbf{2}$ and $\mathbf{2}$ ' underwent hetero Diels-Alder-type cycloaddition with unsymmetrical dienophiles $\mathbf{3}$ in a highly regioselective manner to afford $\mathbf{4}$ bearing the electron-withdrawing group at the $\mathrm{C}-3$ position. In contrast, a similar conversion of the corresponding isoselenazole $1 \mathrm{a}\left(\mathrm{R}^{1}=\mathrm{CH}_{3}, \mathrm{R}^{2}=\mathrm{C}_{6} \mathrm{H}_{5}\right)$ into the same pyridine 4a using DMAD required much higher temperature with a prolonged reaction time, and reaction of 1a with methyl propiolate only gave the recovery even after long-time refluxing in toluene. Interestingly, the reactivity of $N, N$-dimethylpropynamide toward $\mathbf{2 a}$ was much lower than those of methyl propiolate, and electron-rich acetylenes, such as phenylacetylene and diphenylacetylene, were inactive toward the reaction with $\mathbf{2 a}$. These results strongly suggested that inverse-electrondemand Diels-Alder pathway was negligible for the reaction mechanism. However, treatment of $\mathrm{SnCl}_{4}(1.0 \mathrm{~mol}$ amt. $)$ with $\mathbf{2 a}$ or with the reaction mixture of $\mathbf{2 a}$-methyl phenylpropynoate at room temperature formed insoluble materials in the solvent, and in both cases $\mathbf{2 a}$ was completely recovered after neutralization even the reaction mixture was heated at higher temperature for prolonged time. These phenomena suggested that $\mathbf{2}$ were deactivated by the Lewis acid due to their basicity. All the results of reactions of 1, 2, or 2' with symmetrical and unsymmetrical acetylenic dienophiles are presented in Table 1. 
Table 1. Regioselective synthesis of polysubstituted pyridines $\mathbf{4}$ from isoselenazole $\mathbf{1}$, isotellurazoles $\mathbf{2}$, or isotellurazole $T e$-oxides $\mathbf{2}$ ' and acetylenic dienophiles $\mathbf{3}$.

\begin{tabular}{|c|c|c|c|c|c|c|c|c|}
\hline & & $\begin{array}{l}(=\mathrm{Se}) \\
(=\mathrm{Te}) \\
\mathrm{X}=\mathrm{TeO})\end{array}$ & $\begin{array}{l}\text { EWC } \\
\mathrm{R}^{3} \\
\mathbf{3}\end{array}$ & $\frac{\Delta}{-X}$ & & $\mathrm{R}^{2}$ & & \\
\hline \multicolumn{3}{|c|}{ Isochalcogenazole / 1, 2, 2' } & \multicolumn{2}{|c|}{ Dienophile / 3} & \multirow[t]{2}{*}{ Solvent } & \multicolumn{2}{|c|}{ Temp Time } & \multirow{2}{*}{$\begin{array}{c}\text { Yield of } 4 \\
/ \%\end{array}$} \\
\hline $\mathrm{R}^{1}$ & $\mathrm{R}^{2}$ & $X$ & EWG & $\mathrm{R}^{3}$ & & $1{ }^{\circ} \mathrm{C}$ & $/ \mathrm{h}$ & \\
\hline $\mathrm{CH}_{3}$ & $\mathrm{C}_{6} \mathrm{H}_{5}$ & $\mathrm{Se}$ & $\mathrm{COOCH}_{3}$ & $\mathrm{COOCH}_{3}$ & Toluene & Reflux & 12 & $91(\mathbf{4 a})$ \\
\hline $\mathrm{CH}_{3}$ & $\mathrm{C}_{6} \mathrm{H}_{5}$ & $\mathrm{Se}$ & $\mathrm{COOCH}_{3}$ & $\mathrm{H}$ & Toluene & Reflux & 24 & $0^{\mathrm{a}}$ \\
\hline $\mathrm{CH}_{3}$ & $\mathrm{C}_{6} \mathrm{H}_{5}$ & $\mathrm{Te}$ & $\mathrm{COOCH}_{3}$ & $\mathrm{COOCH}_{3}$ & $\mathrm{CH}_{2} \mathrm{Cl}_{2}$ & R.T. & 12 & $91(\mathbf{4 a})$ \\
\hline $\mathrm{CH}_{3}$ & $\mathrm{C}_{6} \mathrm{H}_{5}$ & $\mathrm{Te}$ & $\mathrm{COOCH}_{3}$ & $\mathrm{H}$ & $\mathrm{CH}_{2} \mathrm{Cl}_{2}$ & R.T. & 24 & $79(\mathbf{4 c})^{11}$ \\
\hline $\mathrm{CH}_{3}$ & $\mathrm{C}_{6} \mathrm{H}_{5}$ & $\mathrm{Te}$ & $\mathrm{COOCH}_{3}$ & $\mathrm{C}_{6} \mathrm{H}_{5}$ & Toluene & $140^{\mathrm{b}}$ & 24 & $96(4 \mathrm{~g})$ \\
\hline $\mathrm{CH}_{3}$ & $\mathrm{C}_{6} \mathrm{H}_{5}$ & $\mathrm{Te}$ & $\mathrm{COOCH}_{3}$ & $n-\mathrm{C}_{4} \mathrm{H}_{9}$ & Toluene & $150^{\mathrm{b}}$ & 36 & 90 \\
\hline $\mathrm{CH}_{3}$ & $\mathrm{C}_{6} \mathrm{H}_{5}$ & $\mathrm{Te}$ & $\mathrm{COCH}_{3}$ & $\mathrm{C}_{6} \mathrm{H}_{5}$ & Toluene & $130^{\mathrm{b}}$ & 12 & 93 \\
\hline $\mathrm{CH}_{3}$ & $\mathrm{C}_{6} \mathrm{H}_{5}$ & $\mathrm{Te}$ & $\mathrm{COCH}_{3}$ & TMS & Toluene & $150^{\mathrm{b}}$ & 72 & 71 \\
\hline $\mathrm{CH}_{3}$ & $\mathrm{C}_{6} \mathrm{H}_{5}$ & $\mathrm{Te}$ & $\mathrm{COC}_{6} \mathrm{H}_{5}$ & $\mathrm{COC}_{6} \mathrm{H}_{5}$ & $\mathrm{CH}_{2} \mathrm{Cl}_{2}$ & R.T. & 12 & 88 \\
\hline $\mathrm{CH}_{3}$ & $\mathrm{C}_{6} \mathrm{H}_{5}$ & $\mathrm{Te}$ & $\mathrm{COC}_{6} \mathrm{H}_{5}$ & $\mathrm{C}_{6} \mathrm{H}_{5}$ & Toluene & $150^{b}$ & 24 & quant. \\
\hline $\mathrm{CH}_{3}$ & $\mathrm{C}_{6} \mathrm{H}_{5}$ & $\mathrm{Te}$ & CHO & $\mathrm{C}_{6} \mathrm{H}_{5}$ & Toluene & Reflux & 24 & 83 \\
\hline $\mathrm{CH}_{3}$ & $\mathrm{C}_{6} \mathrm{H}_{5}$ & $\mathrm{Te}$ & $\mathrm{CONMe}_{2}$ & $\mathrm{H}$ & Toluene & 100 & 24 & 90 \\
\hline $\mathrm{CH}_{3}$ & $\mathrm{C}_{6} \mathrm{H}_{5}$ & Te & $p$-TolSO ${ }_{2}$ & $\mathrm{C}_{6} \mathrm{H}_{5}$ & Toluene & 70 & 24 & 59 \\
\hline $\mathrm{H}$ & $\mathrm{C}_{6} \mathrm{H}_{5}$ & $\mathrm{Te}$ & $\mathrm{COOCH}_{3}$ & $\mathrm{COOCH}_{3}$ & Toluene & R.T. & 12 & 69 \\
\hline $\mathrm{H}$ & $\mathrm{C}_{6} \mathrm{H}_{5}$ & $\mathrm{Te}$ & $\mathrm{COOCH}_{3}$ & $\mathrm{H}$ & Toluene & R.T. & 48 & $25^{\mathrm{c} 12}$ \\
\hline $\mathrm{H}$ & & $\mathrm{Te}$ & $\mathrm{COOCH}_{3}$ & $n-\mathrm{C}_{4} \mathrm{H}_{9}$ & Toluene & 150 & 24 & $95(\mathbf{4 e})$ \\
\hline $\mathrm{C}_{6} \mathrm{H}_{5}$ & $\mathrm{C}_{6} \mathrm{H}_{5}$ & $\mathrm{Te}$ & $\mathrm{COOCH}_{3}$ & $\mathrm{COOCH}_{3}$ & $\mathrm{CH}_{2} \mathrm{Cl}_{2}$ & R.T. & 24 & $50(\mathbf{4 b})$ \\
\hline $\mathrm{C}_{6} \mathrm{H}_{5}$ & $\mathrm{C}_{6} \mathrm{H}_{5}$ & $\mathrm{Te}$ & $\mathrm{COOCH}_{3}$ & $\mathrm{H}$ & Benzene & 70 & 6 & $24(\mathbf{4 d})$ \\
\hline $\mathrm{CH}_{3}$ & $\mathrm{C}_{6} \mathrm{H}_{5}$ & $\mathrm{TeO}$ & $\mathrm{COOCH}_{3}$ & $\mathrm{COOCH}_{3}$ & $\mathrm{CH}_{2} \mathrm{Cl}_{2}$ & R.T. & 24 & $77(\mathbf{4 a})$ \\
\hline $\mathrm{C}_{6} \mathrm{H}_{5}$ & $\mathrm{C}_{6} \mathrm{H}_{5}$ & $\mathrm{TeO}$ & $\mathrm{COOCH}_{3}$ & $\mathrm{COOCH}_{3}$ & $\mathrm{CH}_{2} \mathrm{Cl}_{2}$ & R.T. & 48 & $22(\mathbf{4 b})^{\mathrm{c}}$ \\
\hline $\mathrm{CH}_{3}$ & $n-\mathrm{C}_{4} \mathrm{H}_{9}$ & $\mathrm{TeO}$ & $\mathrm{COOCH}_{3}$ & $\mathrm{COOCH}_{3}$ & Toluene & R.T. & 12 & 48 \\
\hline $\mathrm{CH}_{3}$ & $n-\mathrm{C}_{4} \mathrm{H}_{9}$ & $\mathrm{TeO}$ & $\mathrm{COOCH}_{3}$ & $\mathrm{C}_{6} \mathrm{H}_{5}$ & Toluene & $150^{\mathrm{b}}$ & 24 & $42(\mathbf{4 f})$ \\
\hline
\end{tabular}

${ }^{\mathrm{a}}$ Substrate 2 was recovered in quantitative yield. ${ }^{\mathrm{b}}$ Reaction was carried out in a sealed tube. ${ }^{\mathrm{c}} \mathrm{A}$ mixture of uncharacterized polymeric products was mainly obtained besides pyridine 4 . 
Further conversion of pyridines $\mathbf{4 c - f}$ bearing an ester group and a phenyl group at the C-3 and C-4 positions, respectively, into the corresponding 2-azafluorenones $\mathbf{5 c - f}$ was successfully achieved by Friedel-Crafts cyclization using PPA. ${ }^{11}$ Treatment of $\mathbf{4 g}$ bearing a phenyl group at the $\mathrm{C}-2$ position with PPA in a similar manner gave the corresponding 4-azafluorenone $\mathbf{6}$, i.e. an alkyl analogue of naturally-occurring onychine possessing antimicrobial activity, ${ }^{13}$ in $74 \%$ yield. Therefore, a simple, short-step, and efficient entry to the synthesis of derivatives and analogues of 2-aza- and 4-azafluorenone alkaloids having biological and pharmacological activities would be delivered through a hetero Diels-Alder methodology starting from $\mathbf{2}$ or $\mathbf{2}$ '.

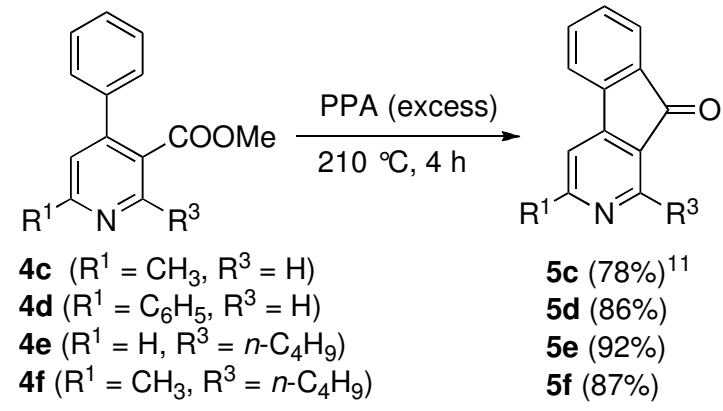

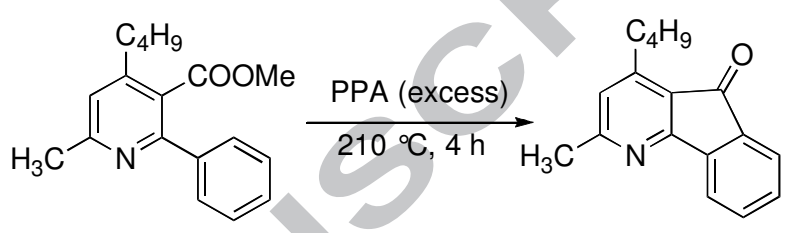

$4 g$

$6(74 \%)$

Computational calculation estimated the unexpectedly high frontier electron density on the tellurium atom along with a usual orbital mode of azadiene moiety in the HOMO of $\mathbf{2 a}\left(\mathrm{R}^{1}=\mathrm{CH}_{3}\right.$, $\mathrm{R}^{2}=\mathrm{C}_{6} \mathrm{H}_{5}$ ), while the carbon and the nitrogen atoms in $\mathbf{2 a}$ possessed low electron density having only a little $n-\pi$ orbital overlapping of the $\mathrm{sp}^{2}$ carbon and nitrogen atoms with the lone pair of the tellurium atom. ${ }^{14}$ Therefore, the high regioselectivity in the formation of polysubstituted pyridines 4 from 2 and 3 would be explained either by usual orbital interaction between the HOMO of the azadiene moiety of $\mathbf{2}$ and the LUMO of the acetylenic part of the dienophiles in the conventional concerted pathway (path A) or by the stepwise pathway initiated by the electrophilic reaction of dienophiles to the electron-rich tellurium atom of isotellurazole ring in $\mathbf{2}$ forming intermediates $\mathbf{C}$ and $\mathbf{D}$ (path B) as shown in Scheme 1. However, the ${ }^{1} \mathrm{H}$ NMR monitoring of the reaction of $\mathbf{2 b}$ $\left(\mathrm{R}^{1}=\mathrm{R}^{2}=\mathrm{C}_{6} \mathrm{H}_{5}\right)$, possessing much lower reactivity toward dienophiles than $2 \mathbf{a}$, with DMAD (5 mol amt.) in an NMR tube at $25^{\circ} \mathrm{C}$ only revealed gradual formation of the signals of pyridine $\mathbf{4 b}$ in the reaction mixture along with decreasing those of substrate $\mathbf{2} \mathbf{b}$, and the signals assignable to possible bicyclic cycloadduct $\mathbf{B}$ or ionic intermediates $\mathbf{C}$ and/or $\mathbf{D}$ were not detected at all throughout the NMR monitoring.

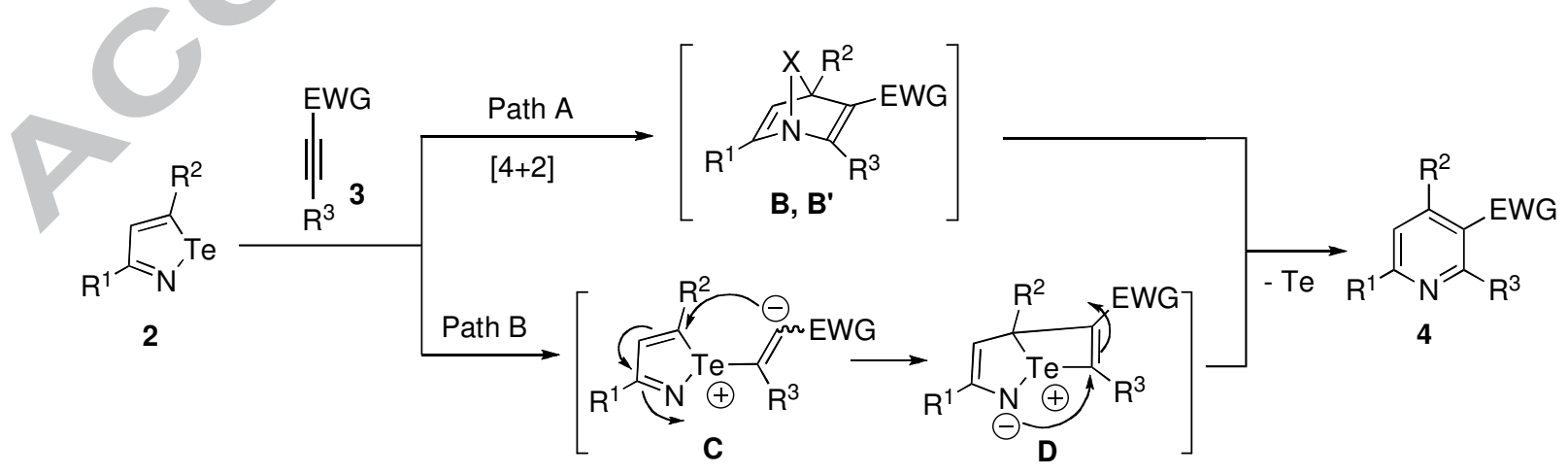


Scheme 1. Plausible pathways for formation of polysubstituted pyridines $\mathbf{4}$ involving a concerted and/or stepwise cyclization of isotellurazole $\mathbf{2}$ with acetylenic dienophiles $\mathbf{3}$.

In conclusion, we found an efficient and versatile synthesis of polysubstituted pyridines 4 starting from isotellurazoles $\mathbf{2}$ or isotellurazole Te-oxides 2' via hetero-Diels-Alder pathway as well as a facile and convenient conversion of $\mathbf{4}$ bearing an ester group at the C-3 position into 2aza- and 4-azafluoreonone alkaloid skeletons. Further applications of the new synthetic protocol to various polycyclic alkaloid ring systems having substituted and fused pyridine cores are now in progress in our laboratory.

\section{Reference and Notes}

1. Hutton, J.; Potts, B.; Southern, D. F., Synth. Commun., 1979, 9, 789-797.

2. Boger, D. L., Tetrahedron, 1983, 39, 2869-2939, and references cited therein.

3. (a) Karpeiskii, M. Y.; Florentev, V. L. Russ. Chem. Reu. (Engl. Trawl.), 1969, 38, 540. (b) Turchi, I. J.; Dewar, M. J. S. Chem. Reu., 1975, 75, 389-437, and the references cited therein. (c) Levin, J. I.; Weinreb, S. M. J. Am. Chem. Soc., 1983, 105, 1397-1398. (d) Thalhammer, F.; Wallfahrer, U.; Sauer, J., Tetrahedron Lett., 1988, 29, 3231-3234. c) Seitz, G.; Wassmuth, H., Chemiker-Zeitung, 1988, 112, 80-81. (e) Levin, J. I., Tetrahedron Lett., 1989, 30, 23552358. (f) Wilkie, G. D.; Elliott, G. I.; Blagg, B. S. J.; Wolkenberg, S. E.; Soenen, D. R.; Miller, Michael M.; Pollack, S.; Boger, D. L., J. Am. Chem. Soc., 2002, 124, 11292-11294. (g) Elgazwy, A. S. S. H. Tetrahedron, 2003, 59, 7445-7463, and the references cited therein.

4. Takikawa, Y.; Hikage, S.; Matsuda, Y.; Higashiyama, K.; Takeishi, Y.; Shimada, K., Chem. Lett., 1991, 2043-2046.

5. Cava, M. P.; Saris, L. E. J. Chem. Soc., Chem. Commun., 1975, 617-618.

6. (a) Campos-Vallette, M. M.; Clavijo C., R. E., Spectrosc. Lett., 1985, 18, 759-766. (b) Baldridge, K. K.; Gordon, M. S., J. Am. Chem. Soc., 1988, 110, 4204-4208. (c) Cozzolino, A. F.; Gruhn, N. E.; Lichtenberger, D. L.; Vargas-Baca, I., Inorg. Chem., 2008, 47, 6220-6226.

7. (a) Bertini, V.; Lucchesini, F. Synthesis 1982, 681-683. (b) Neidlein, R.; Knecht, D., Helv. Chim. Acta, 1987, 70, 1076-1078. (c) Chivers, T.; Gao, X.; Parvez, M., Inorg. Chem., 1996, 35, 9-15. (d) Morkved, E. H.; Lakshmikantham, M. V.; Cava, M. P., Tetrahedron Lett., 1996, 37, 9149-9150. (e) Badyal, K.; Herr, M.; McWhinnie, W. R.; Hamor, T. A.; Paxton, K., Phosphorus, Sulfur, Silicon, Relat. Elem., 1998, 141, 221-229. (f) Rajagopal, D.; Lakshmikantham, M. V.; Morkved, E. H.; Cava, M. P., Org. Lett., 2002, 4, 1193-1195. (g) Cozzolino, A. F.; Vargas-Baca, I.; Mansour, S.; Mahmoudkhani, A. H., J. Am. Chem. Soc., 2005, 127, 3184-3190. (h) Cozzolino, A. F.; Vargas-Baca, I., J. Organomet. Chem., 2007, 692, 2654-2657.

8. (a) Lucchesini, F.; Bertini, V. Synthesis, 1983, 824-827. (b) Lucchesini, F.; Bertini, V.; De Munno, A.; Pocci, M.; Picci, N.; Liguori, M. Heterocycles, 1987, 26, 1587-1593. (c) Pfeiffer, W.-D. Science of Synthesis, 2002, 11, 1005-1020, and the references cited therein.

9. (a) Shimada, K.; Oikawa, S.; Takikawa,Y. Chem. Lett., 1992, 1389-1392. (b) Shimada, K.; Oikawa, S.; Nakamura, H.; Takikawa, Y. Chem. Lett., 1995, 135-136. (c) Shimada, K.; Oikawa, S.; Nakamura, H.; Moro-oka, A.; Kikuchi, M.; Maruyama, A.; Suzuki, T.; Kogawa, H.; Inoue, Y.; Gong, Y.; Aoyagi, S.; Takikawa, Y. Bull. Chem. Soc. Jpn., 2005, 78, 899-905. 
10. Shimada, K.; Moro-oka, A.; Maruyama, A.; Fujisawa, H.; Saito, T.; Kawamura, R.; Kogawa, H.; Sakuraba, M.; Takata, Y.; Aoyagi, S.; Takikawa, Y.; Kabuto, C. Bull. Chem. Soc. Jpn., 2007, 80, 567-577.

11. (a) Shiao, M.-J.; Liu, K.-H.; Lin, P.-Y., Heterocycles, 1993, 36, 507-518. (b) Sreekumar, R.; Rugmini, P.; Padmakumar, R. Synth. Commun., 1998, 28, 2071-2075.

12. (a) Meyers, A. I.; Gabel, Richard A. Heterocycles, 1978, 11, 133-138. (b) Comins, D. L.; Stroud, E. D.; Herrick, J. J. Heterocycles, 1984, 22, 151-157.

13. (a) De Almeida, M. E. I.; Braz, F. R.; von Bulow, M. V.; Gottleib, O. R.; Maia, J. G. S. Phytochemistry, 1976, 15, 1186-1187. (b) Wu, Y. C. Heterocycles, 1989, 29, 463-475. (c) Chaves, M. H.; Santos, L. A.; Lago, J. H. G.; Roque, N. F. J. Nat. Prod., 2001, 64, 240-242. (d) Koyama, J.; Morita, I.; Kobayashi, N.; Osakai, T.; Usuki, Y.; Taniguchi, M. Bioorg. Med. Chem. Lett., 2005, 15, 1079-1082.

14. Theoretical calculation was carried out using the B3LYP / 6-311G (d, p) for C, N, H and 3$21 \mathrm{G}(\mathrm{d})$ for Te level of theory. 


\section{Graphical Abstract}

\section{Regioselective Synthesis of Polysubstituted Pyridines via Hetero Diels-Alder Reaction of Isotellurazoles with} Acetylenic Dienophiles

Kazuaki Shimada, * Yukichi Takata, Yu Osaki, Akiko Moro-oka, Hisashi Kogawa, Maiko Sakuraba, Shigenobu Aoyagi, Yuji Takikawa, and Satoshi Ogawa
1

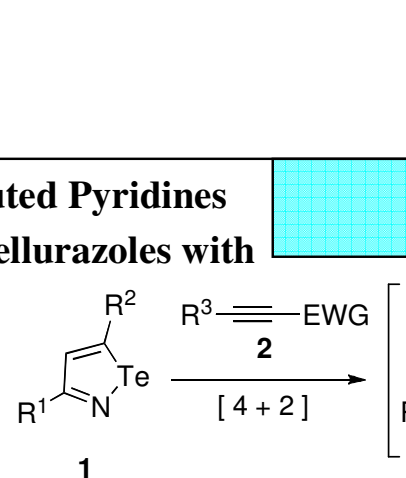

Department of Chemical Engineering, Faculty of Engineering, Iwate University, Morioka, Iwate 020-8551, Japan 